Est Ag 52 (2017) 407-428

\title{
Fe, razón y secularidad: Sus consecuencias en la vida social y política según Ratzinger y Habermas
}

\author{
Domingo Natal Álvarez
}

SumARIO: Aquí se presenta el diálogo entre Habermas y Ratzinger sobre la religión y la razón y sus consecuencias sociales. De esta manera nosotros podemos discutir la relación entre razón y religión en los fundamentos del Estado y el sentido de la secularización actual y ver si nuestro mundo es ya una sociedad más bien post-secular o no.

ABSTRACT: Here we explain the dialogue between Habermas and Ratzinger about the human States and its moral or ethics foundations. In this way, we can see the relations of reason and religion in the secular world and our situation in post-secular one.

\section{Planteamiento del problema con dos grandes personajes en DIÁLOGo}

Se trata aquí de analizar el diálogo mantenido entre ambos autores en la Academia Católica de Baviera el 19.1.2004. J. Habermas, el último representante de la Escuela de Frankfurt, de gran influjo en Europa desde mediados del s. XX, es el defensor de la "ética del discurso" que "hace del diálogo en condiciones de simetría la instancia autorizada de la que proceden las normas que han de regir la convivencia de los ciudadanos de una sociedad pluralista" 1 . Creyentes y no creyentes han de participar "en ese diálogo en pie de igualdad" (RH 6). En fin, en muchas cues-

\footnotetext{
${ }^{1}$ Ratzinger, Joseph - Habermas, Jürgen, Dialéctica de la secularización. Sobre la razón y la religión, Encuentro, Madrid 2006, 6. En las citas RH.
} 
tiones de actualidad, Habermas ofreció opiniones escuchadas por "todo el mundo".

Ahora bien, las polémicas sobre el vestido de las mujeres musulmanas, las caricaturas de Mahoma y los últimos atentados, muestran que a nuestra sociedad "le urge meditar sobre las bases de la convivencia entre ciudadanos creyentes e increyentes" y sobre religión y violencia. En los últimos años Habermas ha mostrado más interés por la religión. Así, en su discurso "Creer y saber" se preguntó por "cómo entender el proceso de secularización en las sociedades post-seculares" (RH 8). Y, cómo han de "convivir y cooperar los ciudadanos creyentes y no creyentes". Pues, hasta ahora, a los creyentes "son los únicos a los que el Estado liberal ha exigido que 'dividan' su identidad en un aspecto público y otro privado" (RH 9). Estos creyentes son los que traducen su identidad a un lenguaje secular, pues: "Según el relato bíblico, el Dios que es amor creó al hombre a su imagen y semejanza: lo hizo libre. Por eso los creyentes piensan que atenta contra el designio divino manifestado en las Escrituras el que un hombre prive de libertad a sus semejantes" (RH 10). Lo mismo hay que decir de la clonación genética. Por eso, la sociedad secular no debe despreciar la sabiduría de las religiones en la defensa de la dignidad humana.

Por su parte, Ratzinger es constante en subrayar el papel de "la razón en el seno de la religión cristiana" (RH 12). Casi desde su inicio ésta es una religión ilustrada: "Al optar por el Dios de los filósofos frente al Dios de la religiones, el cristianismo se suma al esfuerzo de desmitologización del pensamiento racional" (RH 12).

Así, en la Ciudad de Dios, libros VI al VIII contra Varrón, que opta por la teología civil, "san Agustín optará decididamente por la teología natural" (RH 12). Así, el cristianismo quiso ser la "verdadera filosofía", pues: "Cristo se denominó a sí mismo la verdad, no la costumbre". Pero el Estado subordina la religión a la civitas: "Esto supone de hecho la divinización de Roma al tiempo que la devaluación de toda religión" (RH 13).

"El cristianismo, en cambio, entra en escena como síntesis de fe y razón, como religión ilustrada que hace creíble su pretensión de ser la religio vera recurriendo al discurso racional" (RH 10). De ahí nace su pretensión de universalidad y "su rápida difusión en el mundo antiguo". "Ratzinger ha insistido siempre en que esta síntesis de razón y fe es consustancial al cristianismo que no quiera degradarse en fideísmo" (RH 14). Así el cristianismo defiende "la dignidad de la razón" y ser una "reli- 
gión ilustrada". "Evidentemente, no podrá hacer valer este título mas que si no rehúsa el encuentro con la filosofía y la ciencia”, y rechaza el "relativismo que niega la posibilidad de encontrar la verdad". Además: "El encuentro con la razón, también con la razón increyente, es en realidad una exigencia interna del propio cristianismo" (RH 15).

Por eso, R., escribió en la revista Micro-Mega que criticó "severamente la encíclica Fides et Ratio" (RH 16). Este diálogo con Habermas no es algo aislado, en él, y "subraya el compromiso del cristianismo con la razón" (RH 16). Así, R., no estaría nada de acuerdo con la broma sobre "Fides et ratio" que dice: "Los que tenemos fe, tenemos razón".

\section{El TEMA DEL DIÁlogo: Los FUNDAMENTOS MORALES DEL ESTADo}

Se trata de ver "si el Estado liberal secularizado necesita apoyarse en supuestos normativos pre-políticos, es decir, en supuestos que no son el fruto de una deliberación y decisión democrática, sino que la preceden y la hacen posible" (RH 17). Para Habermas, "el propio proceso democrático es capaz de salir garante de sus presupuestos normativos, sin necesidad de recurrir para ello a tradiciones religiosas o cosmovisivas" (RH 17). Es más, ese proceso crea "virtudes políticas" que animan a "la participación activa y comprometida en la gestión de la cosa pública" (RH 17).

Con todo, Habermas admite que la secularización radical provocará "indiferencia política" en los ciudadanos poco "reconocidos en la esfera pública" (RH 17). Así, la falta de control de los mercados y del derecho internacional "fomenta la tendencia a la apatía política". Por el contrario, la secularización se debe entender como "un proceso de aprendizaje recíproco entre el pensamiento laico heredero de la Ilustración y las tradiciones religiosas" (RH 18). Estas aportan "principios éticos" que, en el lenguaje de la razón, fortalecen "los lazos de solidaridad ciudadana sin los cuales el Estado secularizado no puede subsistir" (RH 18).

Para Ratzinger, aunque la democracia es, aún hoy, "el mejor régimen político", hay que "encontrar una base ética común que regule la convivencia de los hombres y los pueblos" (RH 18). La religión aporta mucho pero tiene patologías y precisa de "un diálogo permanente con la razón, diálogo que la purifica y la resguarda de tales excesos" (RH 19). La razón también tiene patologías como la bomba atómica o la clonación humana, y debe "mostrarse dispuesta a escuchar las tradiciones religiosas de la 
humanidad y dejarse purificar por ellas". Así, Ratzinger aboga por la "correlatividad de razón y fe" (RH 20).

Esto debe hacerse en Europa, con el cristianismo, y, en todo el mundo, en diálogo con las otras religiones "que fomente a escala universal el proceso de mutua purificación de razón y religión" (RH 20). En el curso del diálogo entre ambos pensadores: "se reflejó un amplio acuerdo en el plano operativo y ciertas discrepancias importantes en el nivel de los fundamentos" (RH 20). Para Habermas no hay verdad sin diálogo. "Ratzinger cree en una verdad objetiva que el diálogo está llamado a identificar". En todo caso: "Ratzinger y Habermas han dado un bello ejemplo del modo como debemos proceder" (RH 20-1).

\section{J. Habermas. ¿Fundamentos pre-políticos del Estado democráti- co?}

El tema a discutir recuerda la pregunta que el jurista E.W. Böckenförde formuló, mediados los años 60, "de si el Estado liberal y secularizado se alimentaba de presupuestos normativos que él mismo no podía siquiera garantizar" (RH 25). Esto supondría que el Estado recurriría a tradiciones autóctonas, cosmovisivas o religiosas, para hacer la normativa legal adecuada que rija "la colectividad" pero "ajenas a él mismo" (RH 25). Ahora, se trata de fundar un poder político de base secular, "es decir no religiosa o post-metafísica", de conseguir una buena "estabilidad normativa" y crear un Estado liberal que precisa de solidaridad ciudadana pero "que podría desaparecer completamente a causa de una secularización 'descarrillada' de la sociedad" (RH 26).

No se trata de privilegiar a las religiones sino de entender "la secularización cultural y social como un doble proceso de aprendizaje, que fuerce tanto a las tradiciones de la Ilustración como a las enseñanzas religiosas a una reflexión sobre sus respectivos límites" (RH 26). Así, en las sociedades post-seculares habría que pensar las actitudes cognitivas y normativas que el Estado liberal debe pedir "a ciudadanos creyentes y no creyentes en su relación mutua" (RH 27).

\section{a) El Estado liberal se justifica por su discurso libre democrático}

"El liberalismo político", de orientación kantiana, que Habermas defiende "se entiende como una justificación no religiosa y post-metafísi- 
ca de los principios normativos del Estado constitucional democrático" (RH 27). Esta teoría renuncia a la idea del derecho natural u otro derecho basado en cosmovisiones religiosas. Cierto que "la historia de la teología cristiana en la Edad Media, en especial la escolástica española tardía, pertenece ya a la genealogía de los derechos humanos. Sin embargo, los principios de legitimación de un poder estatal neutral en términos de cosmovisión proceden en última instancia de las fuentes profanas de la filosofía de los siglos XVII y XVIII" (RH 27).

Para Habermas, "desde el punto de vista católico, que como es sabido mantiene una relación distendida con el lumen naturale, no hay nada que en principio impida justificar la moral y el derecho autónomamente, es decir, independientemente de las verdades reveladas" (RH 28). Pero, frente al contextualismo y el positivismo jurídico, debe aclarar: "-por qué el proceso democrático se considera un procedimiento legítimo de establecimiento jurídico, si en la medida en que este proceso garantiza condiciones para una opinión y voluntad inclusiva y discursiva, funda la sospecha sobre la aceptabilidad racional de sus resultados" (RH 28).

Y, “- por qué en el proceso constitucional democracia y derechos humanos se entrecruzan en sus principios básicos: la institucionalización jurídica del proceso de establecimiento democrático exige garantizar a la vez derechos fundamentales tanto liberales como políticos" (RH 29). Ahora bien, se trata de: "la constitución que se otorgan a sí mismos los ciudadanos asociados, y no la domesticación de un poder estatal preexistente" (RH 29). Esta última idea provocó que la idea de Böckenförde se vea como la necesidad de fundamentos religiosos o éticos o nacionales para el Estado.

Pero, frente al "Estado constitucional" hegeliano de derechas, la idea "procedimental inspirada en Kant insiste en una justificación autónoma de los principios constitucionales, con la pretensión de ser aceptable racionalmente para todos los ciudadanos" (RH 30). Así, de estos se espera que cumplan las leyes y como autores del derecho "hagan uso activo de sus derechos de comunicación y de participación no sólo por un interés propio bien entendido sino también en interés del bien común, es decir, solidario". Y, esto "no puede imponerse por vía legal" (RH 31).

\section{b) ¿Qué pensar de las aportaciones pre-políticas y su necesidad?}

Entonces, dado que "las virtudes políticas, aunque sólo se obtengan en cantidades mínimas, por así decirlo, en 'calderilla', sean esenciales 
para la existencia de una democracia", "podría decirse que en cierto modo el estatus de ciudadano está insertado en una sociedad civil que se alimenta de fuentes espontáneas, si ustedes quieren, "pre-políticas"” (RH 32). "Así resulta que el 'vínculo unificador' que se echaba en falta es un proceso democrático, en el que a fin de cuentas la cuestión siempre estará en la comprensión correcta de la constitución" (RH 33).

Ahora bien, en otro tiempo un trasfondo religioso común fue útil, pero hoy nos hemos separado de esas "ataduras pre-políticas", y, aunque no estemos dispuestos a dar la "vida "por Niza', no es ya ninguna objeción para la constitución europea" (RH 34). Hoy basta con el "patriotismo constitucional". Incluso: "Para la integración constitucional de una sociedad civil mundial (si es que algún día llega a existir) bastaría con la evidencia moral y con un consenso mundial en lo que respecta a la indignación moral que provocan las violaciones masivas de los derechos humanos" (RH 34). Pues, la solidaridad política solo se dará "cuando los principios de justicia han penetrado previamente el denso entramado de los diferentes conceptos culturales" (RH 35).

Por eso, una modernización social "descarrilada" podría quebrar "el lazo democrático y agotar el tipo de solidaridad en el que se apoya la sociedad democrática, que no puede exigirse por vía legal" (RH 35). Aquí tendría razón Böckenförde para afianzar la solidaridad o los ciudadanos serán "mónadas aisladas, guiados por su propio interés, que utilizarían sus derechos subjetivos como armas los unos contra los otros" (RH $35)$. Esto es lo que pasa hoy con los mercados y los procesos internacionales, ajenos a controles democráticos, y que así, curiosamente, desprestigian la política. Lo mismo que el cristianismo fue garante de los derechos humanos, y, "sin embargo hasta entrados los años sesenta del siglo pasado al catolicismo le costó mucho la relación con el pensamiento laico del humanismo de la Ilustración y del liberalismo político" (RH 37).

Aquí se hace un Excursus sobre la filosofía, la razón y la teología, pues autores como Schleiermacher, Kierkegaard o Feuerbach, reconocen una relación con el Otro ya sea como conciencia mística cósmica o como esperanza de salvación y "solidaridad apremiante con los humillados y ultrajados, que quiere acelerar la salvación mesiánica" (RH 39). Personas religiosas infunden respeto por su "integridad y autenticidad", pero más allá del respeto: "la filosofía tiene motivos suficientes para mostrarse dispuesta a aprender frente a las tradiciones religiosas" (RH 40).

El pensamiento post-metafísico es austero en lo que se refiere a lo ético y en la idea "universalmente vinculante acerca de lo que es una 
vida buena y ejemplar" (RH 40). Lo contrario ocurre con las tradiciones religiosas que han beneficiado a la filosofía con conceptos "normativos de mucho peso", como en W. Benjamin, y aún conservamos en conceptos como: "responsabilidad, autonomía y justificación, historia y memoria, reinicio, innovación y retorno, emancipación y cumplimiento, desprendimiento, interiorización y materialización, individualismo y comunidad. Es cierto que ha transformado el sentido originalmente religioso, pero no lo ha vaciado devaluándolo ni consumiéndolo" (RH 42). Y, así, el hombre es imagen de Dios y exige sus derechos.

\section{c) Relaciones actuales entre creyentes y no creyentes}

Ahora bien, hoy la sociedad post-secular ya cuenta con la persistencia de la religión y la "modernización de la conciencia pública" por la reflexión. "Ambas posturas, la religiosa y la laica, si conciben la secularización de la sociedad como un proceso de aprendizaje complementario, pueden tomar en serio mutuamente sus aportaciones en temas públicos controvertidos también entonces desde un punto de vista cognitivo" (RH 34-44).

Y, poco a poco, la religión tuvo que renunciar a su "monopolio interpretativo y de estructuración de la vida cuando "la secularización del conocimiento, la neutralización del poder estatal y la generalizada libertad religiosa fueron imponiéndose. Con la separación funcional de subsistemas sociales se produce también la separación de la vida de la comunidad religiosa de su entorno social. El papel de miembro de una comunidad religiosa queda así separado del papel de ciudadano" (RH 44).

Con todo, la idea de tolerancia supone que siempre va a haber un cierto disenso entre creyentes y no creyentes, y entre creyentes de diversas religiones, pero "también se espera la misma capacidad de reconocimiento -en el marco de una cultura política liberal- de los no creyentes en su trato con los creyentes" (RH 46). Entonces: "La neutralidad cosmovisiva del poder estatal, que garantiza las libertades éticas para todos los ciudadanos, es incompatible con la generalización política de una visión del mundo laicista". La secularización, no puede negar por principio a la religión su capacidad de verdad, en temas de Estado, ni puede "negar a los conciudadanos creyentes su derecho a realizar aportaciones en lenguaje religioso a las discusiones públicas". Es más, una "cultura liberal" pide a "los ciudadanos secularizados que participen en los 
esfuerzos por traducir aportaciones importantes del lenguaje religioso a un lenguaje más asequible para el público general" (RH 46-7).

\section{J. Ratzinger. Las bases políticas y morales del Estado}

\section{a) La situación actual ante la falta de acuerdo ético y religioso}

Dos fenómenos nuevos definen nuestro mundo: la globalización de todos los poderes y la capacidad del hombre de producir y destruir. Esto plantea, con "máxima urgencia", la búsqueda de cómo las culturas "pueden hallar las bases éticas capaces de fundar adecuadamente la convivencia entre ellas y construir una estructura común jurídicamente responsable del control y del ordenamiento del poder" (RH 51). Por eso, el proyecto de $\mathrm{H}$. Küng de una ética mundial ha tenido gran consenso, a pesar de Spaemann y que "han saltado por los aires las certezas éticas básicas hasta ahora" y la cuestión de "qué es el bien" y "por qué hay que realizarlo incluso en perjuicio propio, es una pregunta fundamental todavía sin respuesta" (RH 52).

Por otra parte, la ciencia ha puesto en crisis gran parte de la ética y no ha ofrecido otra nueva. Por eso, hay que separar lo científico de lo no científico sobre el hombre para mantener "la mirada abierta a la totalidad, a las dimensiones ulteriores de la realidad del hombre, de la que en la ciencia sólo se pueden mostrar aspectos particulares" (RH 53).

\section{b) Fuerza, poder y derecho}

En todo caso, hay que poner el poder bajo el derecho pues: "No debe tener vigencia el derecho del más fuerte, sino más bien la fuerza del derecho". Éste es lo contrario de la violencia, la anarquía y debe estar "por encima de toda sospecha, porque sólo así puede desterrarse la arbitrariedad y se puede vivir la libertad como libertad compartida" (RH 53). Así, el derecho nace de la "formación democrática del consenso" y "la garantía de la participación en la formación del derecho y en la justa administración del poder es la razón esencial a favor de la democracia como la más adecuada de las formas de ordenamiento político" (RH 54).

Ahora bien, la mayoría, sin más, no es suficiente, aunque es lo más común, se necesita una ética. En efecto: "La época moderna ha dado una formulación estable a dichos elementos normativos en las distintas declara- 
ciones de los derechos del hombre, sustrayéndolos al juego de las mayorías". Pues: "Hay valores permanentes que brotan de la naturaleza del hombre y que, por tanto, son intocables en todos los que participan de dicha naturaleza" (RH 55). Y, así, crean derechos Occidente, el Islam y China.

Por otra parte, el poder actual, como vemos en la bomba atómica, se contuvo con la guerra fría, y, ahora se presenta como terrorismo. "En este sentido es inquietante que el terror se esté otorgando en cierto modo una legitimación moral" (RH 57). Pues, esto hace preguntarse si la religión lleva a la curación o a la violencia-destrucción.

Pero, además de preguntarnos por "la cuestión de si hay que considerar la religión como una fuerza moral positiva, ahora debe surgir la duda sobre la fiabilidad de la razón” ( $\mathrm{RH} 58$ ). “¿O no deberían quizá circunscribirse recíprocamente la religión y la razón, mostrarse una a otra los respectivos límites y ayudarse a encontrar el camino?" (RH 59).

\section{c) Presupuestos del derecho: derecho - naturaleza - razón}

Ya en Grecia se dudaba del derecho nacido de las religiones. "Así surgió la idea de que frente al derecho establecido, que podía ser injusto, debía existir un derecho que procediese de la naturaleza, de la esencia del hombre" (RH 59). Con el descubrimiento de América surge el ius Gentium o "derecho de los pueblos": "Se trata de una concepción del derecho como algo previo a la concreción cristiana del mismo, y que debe regular la justa convivencia entre todos los pueblos" (RH 60).

Así, tras la división europea del cristianismo se funda de nuevo el derecho con H. Grocio y S. Pufendorf y otros que "elaboraron la idea del derecho natural como derecho de la razón, que valora la razón como el órgano de la construcción de un derecho común por encima de las fronteras de la fe" (RH 60). Así, el derecho natural ha sido la base de diálogo con la sociedad laica, etsi Deus non daretur, y pluralista que busca los fundamentos del derecho y sus principios. "Pero este instrumento, por desgracia, ha dejado de ser fiable, y por eso en esta conversación mía no quiero basarme en él" (RH 61, cursiva mía). En efecto, de las idea de naturaleza en que se basaba el derecho natural sólo ha quedado la que formuló Ulpiano (a comienzos del s. III d. C): "Ius naturae est quod natura omnia animalia docet"... (RH 62).

Así, del derecho natural sólo han quedado los "derechos humanos, que no son comprensibles si no se acepta previamente que el hombre por sí mismo, simplemente por su pertenencia a la especie humana, es sujeto 
de derechos, y su existencia misma es portadora de valores y normas que hay que descubrir, no que inventar" (RH 62-3. "Quizás hoy habría que complementar la doctrina de los derechos humanos con una doctrina de los deberes humanos y los límites del hombre" (RH 63, cursiva mía).

\section{d) La interculturalidad y sus consecuencias.}

Hoy, la discusión no se reduce sólo al racionalismo occidental o a la tradición cristiana. Pues, en los distintos ámbitos culturales tampoco hay uniformidad. Y aunque la cultura laica, como ha dicho Habermas, "ocupa un papel preponderante y se concibe a sí misma como el elemento unificador, lo cierto es que la comprensión cristiana de la realidad sigue siendo una fuerza activa" (RH 64). Y, unas veces coinciden más pero otras van a "rechazarse recíprocamente". Lo mismo ocurre en el Islam.

En todo caso, la tradición occidental "tampoco puede ser plenamente operativa a escala global. En otras palabras, no existe fórmula universal racional o ética o religiosa, en la que todos puedan estar de acuerdo y en la que todo puede apoyarse. Por eso mismo, la llamada 'ética mundial' sigue siendo una abstracción" (RH 66).

e) Consecuencias prácticas: Las patologías de la razón y de la religión.

Ahora, resulta necesario preguntarse sobre: “¿Qué hacer, entonces? En cuanto a las consecuencias prácticas, estoy en gran parte de acuerdo con lo que ha expuesto Habermas sobre la sociedad post-secularizada, sobre la disponibilidad para aprender y sobre la auto-limitación por ambas partes" (RH 66). Ratzinger dice: "podría resumir mi visión personal en dos tesis":

"1 ${ }^{a}$.- Hemos visto que en la religión hay patologías altamente peligrosas que hacen necesario considerar la luz divina de la razón como una especie de órgano de control por el que la religión debería dejarse purificar y regular una y otra vez, cosa que ya pensaban los Padres de la Iglesia" (RH 66-7). Ahora bien: "también hay patologías de la razón, una arrogancia de la razón que no es menos peligrosa; más aún, considerando su efecto potencial, es todavía más amenazadora: la bomba atómica, el ser humano entendido como producto. Por eso, también a la razón se le debe exigir a su vez que reconozca sus límites y que aprenda a escuchar las grandes tradiciones religiosas de la humanidad. Si se emancipa totalmente y renuncia a dicha disposición a aprender, si renuncia a la correlación, se vuelve des- 
tructiva". Así que hay "una correlación de razón y fe, de razón y religión, que están llamadas a purificarse y regenerarse recíprocamente, que se necesitan mutuamente y deben reconocerlo" (RH 67-8).

$2^{a}$. Por otra parte, en la cultura actual, la fe cristiana y la racionalidad occidental son los "agentes principales": "Ambas caracterizan la situación mundial como ninguna otra fuerza cultural. Pero ello no significa que nos podamos desentender de las demás culturas como si fueran una quantité-négligeagle". Esta arrogancia occidental ya la estamos pagando muy cara. Por eso: "Es importante que las dos grandes componentes de la cultura occidental estén dispuestas a escuchar y desarrollen una auténtica correlación también con esas culturas" (RH 68). Así, se abrirán a la "esencial relación complementaria de razón y fe", "de modo que pueda crecer un proceso universal de purificación en el que al final puedan resplandecer de nuevo los valores y las normas que en cierto modo todos los hombres conocen o intuyen, y así pueda adquirir nueva fuerza efectiva entre los hombres lo que mantiene cohesionado el mundo" (RH 68). Expondremos con más detalle este tema de la razón y la religión, y sus patologías, en otro escrito, al analizar el discurso de Ratisbona.

\section{Discurso al Parlamento Federal Alemán}

Para completar algunos aspectos de los temas discutidos por Ratzinger y Habermas nos acercarmos a los discursos de Benedicto XVI al Parlamento Alemán, al Parlamento Británico y a la Asamblea de la ONU. De este discurso en la ONU el New York Post escribió: "Si a alguién no le conmovió, es que no está vivo"2.

El discurso al Bundestag, al que John L. Allen ha llamado "el mejor discurso de su pontificado", es una gran síntesis del pensamiento del Papa sobre la democracia en el Estado liberal. Die Spiegel calificó el discurso de "valiente y brillante" y el Bild de "pieza maestra". El Frankfurter Allgemeine Zeitung publicó integra la intervención papal y London Guardian hizo un amplio comentario. Esto mostraría que "la religión tiene un espacio social y mediático, una cierta visibilidad social. Sin embargo, como se sabe, no todo el mundo está de acuerdo con esta inter-

2 Benedicto xvi, Últimas conversaciones con Peter Seewald, Mensajero, Bilbao 2016, 260.

${ }^{3}$ García, Rafael D. - Blanco, Pablo (Eds.), Benedicto XVI habla sobre: Cultura y sociedad, Palabra, Madrid 2013, 18. Comentarios de P. Blanco (P.), D. Walsh y R. D. García (GP), en adelante CS. 
vención"3. Para R. D. García Pérez, este discurso "pasará a la historia como una de las intervenciones más relevantes de su pontificado" (GPCS 173).

Por lo demás: La fe -explicaba Lammet- ha informado la historia de Alemania de Lutero a la Kulturkampf, de la unificación de Bismarck a la II $^{a}$ Guerra Mundial y de ésta a su Ley Fundamental: "ante Dios y ante los hombres" (GP-CS 173-4). Para "el presidente del Bundestag, fe y razón constituyen la dos culturas de Alemania" (GP-CS 174). Por lo demás, R., siempre mostró una gran capacidad para llevar sus ideas "al público que le escucha sin por ello renunciar al contenido esencial de su discurso" (GP-CS 174). El Papa mira a los ecologistas y la tradición judía, pues: "El principio de la creación podía poner un fundamento más sólido a este imprescindible respeto al medio ambiente". Y, con Pascal, dice: "mejor que todos nos comportemos como si Dios existiese" (P-CS 19).

En fin, la democracia lleva en su corazón "la justicia y el derecho", insiste el Papa. Y, contra toda dicotomía, "pedía una justicia política, así como una política que se avenga a los dictámenes de la justicia, y por tanto de la ética" (P-CS 20). El nazismo con su relativismo se hizo poder cruel y eliminó toda moral y resistencia. "La referencia a la ética y a la verdad podrían evitar volver a caer en esa misma dictadura" (P-CS 21).

En un Estado a-moral, el hombre se hace manipulador y destructor. Pero los "derechos humanos" y "la libertad religiosa" no necesitan del confesionalismo. "Basta con estas instancias comunes y naturales. La 'laicicidad positiva' es una consecuencia directa de los conceptos de libertad y de justicia" (P-CS 22). "La realidad actual alemana es multicultural, multikulti, como (se) dice. Verdad y laicidad son dos instancias complementarias en una sociedad plural".

"La verdad no necesita, pues, del fundamentalismo ni del pensamiento único para hacerse valer en la sociedad. Ella misma se acaba por imponer" (P-CS 23). Pero no valen las meras mayorías y se precisa la ética como ocurrió en la "resistencia" que apelaba "a la razón, a la conciencia, a la justicia, a la condición humana, a la dignidad de la persona" (P-CS 24). En lo político, el Papa remite a la razón no a la fe. Es lo lógico en las nuevas relaciones "entre la fe y la razón, entre Iglesia y Estado, y del concepto de 'lacidad positiva', en última instancia. Siendo realidades distintas, no tendrían por qué presentarse distantes. Pueden mirar-desde la diferencia- en la misma dirección" (P-CS 24).

Así, el Papa inició su discurso con la oración de Salomón que pide a Dios "un corazón dócil, para que sepa juzgar a tu pueblo y distinguir el 
bien del mal (1 R 3,)". De hecho, la política es "un compromiso por la justicia" para crear "las condiciones básicas para la paz". El político buscará el éxito, pues sin él no "tendría la posibilidad de una acción política efectiva. Pero el éxito está subordinado al criterio de la justicia, a la voluntad de aplicar el derecho y a la comprensión del derecho.

$\mathrm{El}$ éxito puede ser también una seducción y, de esta forma, abre la puerta a la desvirtuación del derecho, a la destruccion de la justicia. 'Quita el derecho y, entonces, ¿qué distingue el Estado de una gran banda de bandidos?', dijo en cierta ocasión san Agustín (De civitate Dei, IV, 4,1). Nosotros los alemanes sabemos por experiencia que estas palabras no son una mera quimera" (...) "Servir al derecho y combatir el dominio de la injusticia es y sigue siendo el deber fundamental del político" (CS 102).

Dados los poderes del hombre actual: "La petición salomónica sigue siendo la cuestión decisiva ante la que se encuentra también hoy el político" (CS 103). La legalidad sin justicia es un gran atropello. Esta convicción movió a los luchadores contra el nazismo y "otros regímenes totalitarios, prestando así un servicio al derecho y a toda la humanidad" (CS 103).

Hoy no es tan fácil saber lo que es justo o injusto. Antes se remitía a la razón creadora de Dios. Estoicismo y cristianismo crearon el derecho y las bases de "la cultura jurídica de la humanidad". Después, a partir de esta idea precristiana de derecho y filosofía se inicia el camino que lleva de "la Edad Media cristiana, al desarrollo jurídico de la Ilustración, hasta la Declaración de los derechos humanos y nuestra Ley Fundamental Alemana, con la que nuestro pueblo reconoció en 1949 'los inviolables e inalienables derechos del hombre como fundamento de toda comunidad humana, de la paz y de la justicia en el mundo"' (CS 104-5).

Para el desarrollo de esos derechos fue decisivo que los teólogos abandonaran el derecho de las religiones y optaran por "la razón y la naturaleza" como "fuente jurídica" universal. "Esta opción la había tomado ya san Pablo cuando, en su Carta a los Romanos, afirma: 'Cuando los paganos, que no tienen ley (la Torá de Israel), cumplen naturalmente las exigencia de la ley, ellos... son ley para sí mismos. Esos tales muestran que tienen escrita en su corazón las exigencias de la ley, contando con el testimonio de su conciencia...' (Rm 2,14s)".

"Aquí aparecen los dos conceptos fundamentales de naturaleza y conciencia, en los que conciencia no es otra cosa que el 'corazón dócil' de Salomón, la razón abierta al lenguaje del ser” (CS 105). Así, las bases del 
derecho eran claras pero, en el último siglo cambió del todo la situación. Y: "La idea del derecho natural es considerada hoy una doctrina católica más bien singular, sobre la que no vale la pena discutir fuera del ámbito católico, de modo que casi nos avergüenza la sola mención del término. Quisiera indicar brevemente cómo se llegó a esta situación" (CS 105).

Según el criterio positivista, "entre el ser y deber ser existe un abismo infranqueable". Así, para Kelsen, la naturaleza es un conjunto de "datos objetivos" sin sentido "hacia el Ethos y el derecho". Hoy reina el positivismo en nuestra "conciencia pública" y las fuentes "del ethos y del derecho quedan fuera de juego. Esta es una situación dramática que afecta a todos y sobre la cual es necesaria una discusión pública; una intención esencial de este discurso es invitar urgentemente a ella" (CS 106).

En este mundo positivista funcional, hay un clima inhumano como de cemento armado en el que ya no cuenta Dios. Con todo, "en este mundo autoconstruido recurrimos en secreto igualmente a los 'recursos' de Dios, que transformamos en productos nuestros. Es necesario volver a abrir las ventanas, hemos de ver nuevamente la inmensidad del mundo, el cielo y la tierra, y aprender a usar todo esto de modo justo" (CS 107).

De hecho: Gente joven (ecologista) vio que en nuestras relaciones con la naturaleza algo no funcionaba, pues el mundo no es solo nuestro sino que la tierra tiene una dignidad que debemos respetar como "hay también una ecología del hombre" a respetar sin manipular a su antojo. "El hombre no es solamente una libertad que él se crea por sí solo. El hombre no se crea a sí mismo. Es espíritu y voluntad, pero también naturaleza, y su voluntad es justa cuando él respeta la naturaleza, la escucha, y cuando se acepta como lo que es y admite que no se ha creado así mismo. Así, y solo de esta manera, se realiza la verdadera libertad humana" (CS 108).

Luego, a partir de la idea de Dios creador se desarrollaron los derechos humanos, la "igualdad de todos los hombres", su "dignidad" y "la responsabilidad de cada persona. Esta idea de razón es nuestra "memoria cultural", sin ella muere la cultura nacida de Jerusalén, Atenas y Roma, "del encuentro entre la fe en el Dios de Israel, la razón filosófica de los griegos y el pensamiento jurídico de Roma. Este triple encuentro configura la íntima identidad de Europa. Con la certeza de la responsabilidad del hombre ante Dios y reconociendo la dignidad inviolable del hombre, de cada hombre, este encuentro ha fijado los criterios del derecho; defenderlo es nuestro deber en este momento histórico" (CS 109).

$\mathrm{Al}$ rey Salomón se le concedió lo que pedía. Y, hoy “¿Qué pediríamos? Pienso que, en último término, también hoy no podríamos desear 
otra cosa que un corazón dócil: la capacidad de distinguir el bien del mal, y así establecer un verdadero derecho, de servir a la justicia y la paz. Muchas gracias" (CS 110). Con la súplica de Salomón, el Papa sitúa en la conciencia "el núcleo de sus reflexiones". Pero, es "una petición a Dios y, por tanto, asume como punto de partida la incapacidad del hombre para alcanzar por sus propios medios la regeneracion interior, la superación del mal que anida en su alma y puede nublar su conciencia”. Aplicado al contexto postmoderno el Papa señala: "que todo intento de auto-redención humana resulta no solo ilusorio, sino destructivo". Así, el Papa sale al paso de uno de los peligros de toda sociedad política, incluso la democrática: "La tentación de construir una sociedad perfecta haciendo violencia a la propia realidad humana, siempre limitada" (GP-CS 182).

Es la tentación de fiarlo todo a la "política" y la "liberación" mágica estructural sin ética. Pero: "Son estas las que habría que cambiar para conseguir la ciudad perfecta, pero para ello resulta preciso renunciar al ethos personal, es decir, renunciar a la responsabilidad y a la libertad y, en definitiva, a la conciencia de cada ciudadano". El problema radica aquí: en una idea de conciencia capaz de "superar la dicotomía entre libertad y verdad que ha caracterizado el pensamiento contemporáneo" (GP-CS 183).

Pues, el pensamiento liberal subjetivista y el dogmatismo objetivista no concilian "libertad y verdad, como si de realidades opuestas e incompatibles se tratase" (GP-CS 183). Así, unos creen en un subjetivismo como fuente de "toda sociedad democrática" y otros fían a "las estructuras democráticas -como hemos señalado- la preservación de ese orden ético que toda sociedad necesita para subsistir" (GP-CS 183).

Así, la libertad y la verdad pierden su sentido. Pero el Papa recupera la tradición clásica y a los Padres de la Iglesia y la conciencia humana entendida como "la ventana que abre al hombre el panorama de la verdad común que nos sustenta y sostiene a todos, haciendo posible que seamos una comunidad de querer y de responsabilidad apoyada en la comunidad de conocimiento"4.

No se trata de la "mera auto-conciencia del yo" ni de una coraza subjetivista sino de "la comprensión de la conciencia que Newman defendió en su tiempo como 'la presencia clara e imperiosa de la voz de la verdad en el sujeto"'5 (GP-CS 185). Es la presencia de la memoria de Dios en el hombre, desarrollada por S. Pablo y los Padres de la Iglesia,

${ }^{4}$ Ratzinger, Joseph, Verdad, valores, poder. Piedras de toque de la sociedad pluralista, Palabra, Madrid 1995, 49, n. 13.

5 Ibid., 59. 
pues el hombre imagen de Dios tiene una íntima tendencia a lo que es "conforme a Dios" y percibe en su ser una armonía de unas cosas y rechazo de otras. "A esta 'capacidad de reconocimiento' de lo que es verdadero, de aquello que se conforma a su propio modo de ser, Ratzinger lo denomina "“anamnesis del Creador". Esta anamnesis-memoria permite a Pablo afirmar que "los paganos son su propia ley" $(\mathrm{Rm} 2,14)$. "El apóstol de las gentes no lo dice en el sentido moderno de autonomía, incompatible con toda idea de auto-trascendencia -aclara Ratzinger-, sino en el sentido más profundo de que 'el propio yo es el lugar de la auto-superación más completa en el que somos tocados por Aquel del que venimos y al que vamos' (n.15, ibid., 64-68)" (GP-CS 185-6). Esta es la experiencia agustiniana de la "memoria Dei" o como dice Heidegger: el hombre es "memoria del Ser".

La conexión íntima de la conciencia y la verdad quedó velada en la modernidad por el deseo de preservar la libertad humana frente al despotismo autoritario. "El triunfo del totalitarismo nazi, expresión emblemática de un nihilismo inédito en la historia, se efectuó, en efecto, a costa de la libertad y de la verdad" (GP-CS 186).

Así dice el Papa: si la conciencia se reduce a lo subjetivo en "la religión y la moral, la crisis de Occidente no tiene remedio y Europa está destinada a la involución. En cambio, si la conciencia vuelve a descubrirse como lugar de escucha ante Dios y los hermanos en la humanidad, que es la fuerza contra cualquier dictadura, entonces hay esperanza de futuro" (GP-CS 187).

Por tanto, hay que volver al personalismo, que supera el intrumentalismo destructivo y abre la conciencia dócil al ser para escuchar "la naturaleza" y la nueva sensibilidad ecologista que incluye al ser humano. Así: "por una vía más adaptada a la sensibilidad contemporánea, el Papa retoma, pasando por la conciencia y su apertura al ser y, en definitiva, a Dios, la conexión entre naturaleza y razón que durante siglos ha servido para fundamentar racionalmente el derecho" (GP-CS 188).

Por tanto, no carece de sentido plantearse "si la razón objetiva" presente "en la naturaleza" no supone "una razón creativa, un Creator Spiritus", dado que sólo una conciencia purificada y un corazón dócil, como el que Salomón pidió a Dios, "es capaz de escuchar la naturaleza y fijar así los criterios del derecho, de manera que este siga cumpliendo el papel de garante de la libertad que le es propio" (GP-CS 189).

Pero la decadencia de Europa que reduce la fe a la conciencia sin que "ilumine al hombre en su actuación pública, pone en peligro la 
misma racionalidad del orden social, y, por tanto, del derecho" (GP-CS 190). Por eso, sin ser una receta política para sociedad actual, el cristianismo apela a la necesidad de la ética en la acción política y económica. Siempre lo intentó así y la sociedad lo asumió en buena parte. Por eso: "La propuesta que una vez hiciera Benedicto XVI de invertir la fórmula de Grocio, y vivir y pensar veluti si Deus daretur, como si Dios existiese, adquiere así pleno sentido (n.24. J. Ratzinger, El cristiano en la crisis de Europa. Cristiandad, M. 2005, 47)" (GP-CS 191).

\section{Discurso en Westminster Hall a los representantes de Gran BRETAÑA}

Como ya decía Chesterton: el problema de la cultura y la sociedad actual no es la falta de fe sino de razón. Sobran dogmatismos y supersticiones ideológicas. La razón y la religión deben tener carta de ciudadanía en la universidad, en la cultura y la sociedad. De hecho, la razón no es exclusiva de una religión y todas deben tenerla en cuenta. "También el cristianismo ha tenido sus encuentros (y también desencuentros) con la razón, pero esta tensión debe mantenerse viva a lo largo del tiempo" (PCS 16-7).

El Papa expresa su estima al "Parlamento" por su "profunda influencia en el desarrollo de los gobiernos democráticos", "especialmente en la Commonwealth" y "el mundo de habla inglesa". Esta "tradición jurídica -'common law"'- llevó a los gobiernos su visión "de los respectivos derechos y deberes del Estado y de las personas, así como de la separacion de poderes, siguen inspirando a muchos en todo el mundo" (CS 93).

El recuerdo de T. Moro "buen servidor" social y "fiel a su conciencia" que afrontó "la perenne cuestión de la relación entre lo que se debe al César y lo que se debe a Dios, me ofrece la oportunidad (dice el Papa) de reflexionar brevemente con ustedes sobre el lugar apropiado de las creencias religiosas en el proceso político" (CS 94).

Gran Bretaña ha alcanzado un feliz equilibrio, entre la autoridad del gobierno y los derechos de los ciudadanos, "y se ha configurado como una democracia pluralista que valora enormemente la libertad de expresión, la libertad de afiliación política y el respeto por el papel de la ley, con un profundo sentido de los derechos y deberes individuales y de la igualdad de todos los ciudadanos ante la ley" (CS 94). La Doctrina Social de la Iglesia tiene mucho en común con esta perspectiva en la "dignidad 
única" de la persona humana, imagen de Dios, y "su énfasis en los deberes de la autoridad civil para la promocion del bien común" (CS 94).

La democracia se basa en principios éticos y la falta de esas bases es la causa de la crisis económica, pues, toda política tiene retos morales. Un ejemplo de esto es el gran logro de este Parlamento: "la abolición del tráfico de esclavos" pues el camino de ese gran éxito se hizo de "firmes principios éticos, enraizados en la ley natural, y brindó una contribución a la civilización de la cual esta nación puede estar orgullosa" (CS 95). Con todo, la religión no impone soluciones políticas concretas. Su papel es "iluminar" la razón para descubrir "principios morales objetivos". Esta tarea no siempre fue positiva por las deformaciones de la religión, sus sectarismos y fundamentalismos, causa de problemas sociales. Estas distorsiones "surgen cuando se presta una atencion insuficiente al papel purificador y vertebrador de la razón a la religion" (CS 96).

El abuso de la razón "provocó la trata de esclavos" y otros "males sociales" como "las ideologías totalitarias del siglo XX". Por eso deseo indicar que el mundo de la razón y el mundo de la fe -el mundo de la racionalidad secular y el mundo de las creencias religiosas- necesitan uno de otro y no deberán tener miedo de entablar un diálogo profundo y continuo, por el bien de nuestra civilización (cursiva mía). En otras palabras, la religión no es un problema que los legisladores deban solucionar, sino una contribucion vital al debate nacional" (CS 96).

El Papa está preocupado por la marginación de la religión incluso en países tolerantes e invita a todos "a buscar medios de promoción y fomento del diálogo entre fe y razón en todos los ámbitos de la vida nacional" (CS 97). De decho, la actual colaboración entre Gran Bretaña y la Santa Sede es positiva en el ámbito de la paz, los derechos humanos, la difusion de la democracia o la reduccion de la deuda y el comercio justo, y busca "la responsabilidad medioambiental, en beneficio de todos" (CS 97).

El Gobierno británico destina el $0,7 \%$ de su renta a ayuda al desarrollo; es alentador el crecimiento mundial de la solidaridad con los pobres. El mundo ha visto los ingentes recursos empleados en rescatar "instituciones financieras consideradas 'demasiado grandes para que fracasen'. Desde luego, el desarrollo humano integral de los pueblos del mundo no es menos importante. He aquí una empresa digna de la atención mundial, que es en verdad 'demasiado grande para que fracase"' (CS 98, cursiva mía). 
La Santa Sede y Gran Bretaña promueven esos valores en todo el mundo y en su país "por el bien de los ciudadanos, en consonancia con la histórica costumbre de este Parlamento de invocar la asistencia del Espíritu sobre quienes buscan mejorar las condiciones de toda la humanidad". Para desarrollar esa cooperación, los grupos religiosos católicos necesitan "libertad de actuación conforme a sus propios principios y convicciones específicas basadas en la fe y el magisterio oficial de la Iglesia. Así se garantizarán derechos fundamentales como la libertad religiosa, la libertad de conciencia y la libertad de asociación" (CS 98-9). Los ángeles que nos contemplan desde el cielo del Parlamento recuerdan la tradición que desarrolló la democracia británica y "que Dios vela constantemente para guiarnos y protegernos; $y$, a su vez, nos invitan a reconocer la contribucion vital que la religión ha brindado y puede seguir brindado a la vida de la nación". Así, el Papa ofrece "oraciones por ustedes y por los fructuosos trabajos de las dos Cámaras del Parlamento" (CS 99).

\section{Discurso en la Asamblea General de la ONU (18.4.2008)}

"El discurso ante las Naciones Unidas recordaba las dos estatuas de las que hablaba Viktor Frankl: la de la libertad en la costa este, que debería ir acompañada por la de la responsabilidad en la costa oeste". Así, no hay que optar "entre ciencia y ética" sino por "un método científico" que respete "los imperativos éticos". Además, hoy los católicos creen que las normas para un gobierno justo "son accesibles a la razón, prescindiendo del contenido de la revelación" (P-CS 15).

El Papa desea que la ONU sea un organismo que "'armonice los esfuerzos de las Naciones para alcanzar los fines comunes' de la paz y el desarrollo (cfr. Carta de las Naciones Unidas, art. 1.2-1.4)". Como dijo Juan Pablo II: que la ONU sea "un centro moral" donde todos los pueblos del mundo se sientan en su casa como una "familia de naciones" (CS 57).

Los principios fundacionales de la ONU: "el deseo de la paz, la búsqueda de la justicia, el respeto de la dignidad de la persona, la cooperación y la asistencia humanitaria" son "las justas aspiraciones del espíritu humano y constituyen los ideales que deberían estar subyacentes en las relaciones internacionales" (CS 58). Según Pablo VI, la ONU debe ser "un ejemplo de cómo los problemas y conflictos relativos a la comunidad mundial pueden estar sujetos a una reglamentación común" (CS 58). 
Pues, la seguridad, el desarrollo, la reducción de las desigualdades, la protección del medio y los problemas de la globalización, requieren una acción internacional "con una disponibilidad para actuar de buena fe, respetando la ley y promoviendo la solidaridad con las regiones más débiles del planeta" (CS 58-59).

En las relaciones internacionales hay que reconocer las normas del "bien común" y la "la libertad humana". Esas reglas promueven esos dos bienes frente a lo que obstaculiza "su realización efectiva" y daña "la dignidad de toda persona humana" (CS 59). Hay que proteger la vida y la creación con un uso racional de la tecnología y la ciencia. No hay que elegir entre "ciencia y ética" sino buscar un "método científico" con imperativos éticos", pues: "Todo Estado tiene el deber primario de proteger a la propia población de violaciones graves y continuas de los derechos humanos, como también de las consecuencias de las crisis humanitarias, ya sean provocadas por la naturaleza o por el hombre" (CS 60).

Si un Estado no lo hace, la comunidad internacional debe intervenir con los medios "previstos por la Carta de las Naciones Unidas" y otros tratados. La "responsabilidad de proteger" estaba en el antiguo ius gentium de la gobernanza y F. de Vitoria lo aplicó a las relaciones entre todos los pueblos. Este principio hace "referencia a la idea de la persona como imagen del Creador, al deseo de una absoluta y esencial libertad" (CS 60-1).

Así, la Declaración Universal de los Derechos Humanos se basa en la dignidad de la persona, en religiones y culturas con un deseo común: poner a la persona en el corazón de las instituciones de la sociedad, y "de considerar a la persona humana esencial para el mundo de la cultura, de la religión y de la ciencia. Los derechos humanos son presentados cada vez más como el lenguaje común y el sustrato ético de las relaciones internacionales. Al mismo tiempo, la universalidad, la indivisibilidad y la interdependencia de los derechos humanos sirven como garantía para la salvaguardia de la dignidad humana" (CS 61).

"Estos derechos se basan en la ley natural inscrita en el corazón del hombre y presente en las diferentes culturas y civilizaciones": No es justo dañar la dignidad de la persona ni sus derechos ni negarlos por relativismo. Promover estos derechos es "clave para buscar "el bien común", "extirpar las desigualdades", "aumentar la seguridad", detectar la "justicia e injusticia", y valorar el "desarrollo y pobreza" (CS 62).

Así, "la Declaración Universal ha reforzado la convicción de que el respeto de los derechos humanos está enraizado principalmente en la 
justicia, que no cambia, sobre la cual se basa también la fuerza vinculante de las proclamaciones internacionales" (CS 63). "Esta intuición fue expresada ya muy pronto, en el siglo V, por Agustín de Hipona, uno de los maestros de nuestra herencia intelectual. Decía que la máxima 'no hagas a otros lo que no quieres que te hagan a ti en modo alguno puede variar, por mucha que sea la diversidad de las naciones' (Doc. christiana, III, 14)" (CS 63-64).

Por ello, hay que aceptar el diálogo para crear consensos basados en valores objetivos. Las religiones, desde la libertad, deben buscar el diálogo pues separadas de la política producirán "grandes beneficios" a todos. Así, la fe, no es intolerancia y conflicto sino respeto a "la verdad, la coexistencia, los derechos y la reconciliación" (CS 65). Y, para ser ciudadano no hay que dejar la fe pues hay libertad religiosa, y: "Los derechos asociados con la religión necesitan protección sobre todo si se los considera en conflicto con la ideología secular predominante o con posiciones de una mayoría religiosa de naturaleza exclusiva" (CS 65).

Y, la garantía de la libertad religiosa es el "libre ejercicio del culto" y su dimension pública con "la posibilidad de que los creyentes contribuyan a la construcción del orden social. A decir verdad, ya lo están haciendo" con pobres y marginados. Ignorar el valor social de "la dimensión religiosa" y de "la búsqueda del Absoluto -expresión por su propia naturaleza de la comunión entre personas- privilegiaría efectivamente un planteamiento individualista y fragmentaría la unidad de la persona" (CS 66).

La presencia del Papa en la ONU manifiesta su aprecio a sus tareas y la colaboración de la Iglesia, sobre todo "en la esfera ética y moral y con la libre actividad de los propios fieles". La ONU es un centro privilegiado al que la Iglesia aporta su experiencia de humanidad desarrollada por siglos "entre pueblos de toda raza y cultura, y a ponerla a disposición de todos los miembros de la comunidad internacional" (CS 66-7).

Esta experiencia protege los derechos de todos basados en la naturaleza trascendente de la persona y permite a hombres y mujeres vivir su fe y la búsqueda de Dios. Esta dimensión debe ser reforzada para "fomentar la esperanza de la humanidad en un mundo mejor y crear condiciones propicias para la paz, el desarrollo, la cooperación y la garantía de los derechos de las generaciones futuras".

La encíclica Spe salvi, subraya que la búsqueda de "rectos ordenamientos para las realidades humanas es una tarea de cada generación" (n.25). Para los cristianos, esta esperanza nace de Jesucristo."Precisamente por eso la Iglesia se alegra de estar asociada con la actividad de esta 
ilustre organización, a la cual está confiada la responsabilidad de promover la buena voluntad en todo el mundo" (CS 67). 